on the other hand, still refers to "unit characters" as late as p. 361 of the book.

The general approach is authoritative; the reader is offered answers rather than the questions, experiments and arguments that underlie them. Thus, while the book does a good job of conveying information, it does little to either exercise or exorcize the mind.

\author{
K. R. LEWIS \\ Botany School, Oxford
}

\title{
A GENERAL THEORY OF GROWTH AND DISEASE
}

AN ENQUIRY CONCERNING GROWTH, DISEASE AND AGEING. P. R. J. Burch. Oliver and Boyd, London, 1968. Pp. viit 213. 63 s.

This is a book which everyone interested in the problems of growth, diseasesusceptibility and ageing should read. Many people will find part or all of it provoking. However, when they have finished reading it, they should have a much clearer idea of both the deficiencies and the strength of their own approaches to these problems. A few readers may even modify their own theories to account for some of the phenomena that the author of this book seeks to explain.

Dr Burch proposes a general theory of normal growth in vertebrates, and interprets ageing and many disease processes in terms of the breakdown of the system controlling growth. In outline the theory is as follows: the stable comparators necessary for the homeostatic control of growth of tissues and organs are to be found in cells of the lymphoid system. These cells produce specific mitotic control proteins (MCP's) which stimulate symmetrical mitosis in the target-tissues, each of which contains a specific tissue coding factor (TCF). As a result of growth the amounts of affector, derived from the TCF of the particular tissue, in the general circulation rise and exert negative feedback on the production of the appropriate MCP. MCP's and TGF's are both considered to be polypeptides. For a particular tissue the MCP and TCF differ only in their prosthetic groups. The MCP and TCF may either be humoral or carried by lymph cells. Such a theory accounts for the central control of certain growth processes and for associations, such as those involving the thymus, between the lymphoid system and abnormal growth. In a chapter on leukemias and other diseases involving disturbed growth of the lymphoid system the author indicates how neoplastic disease might be brought about by failures in this mechanism of growthcontrol.

The main evidence for the theory put forward in the chapters on the age-specific onset rates of a wide range of diseases. These include osteoarthritis, duodenal ulcers and diabetes mellitus. These diseases are interpreted as autoaggressive diseases in which the MCP-TCF control system has been upset by mutations in the comparator cells. For each disease a specific latent period before detection is adopted and only a particular proportion of the general population is considered to be genetically susceptible. These susceptible individuals have cells in which a particular MCP-TCF coding region is likely to be affected by mutation. The epidemiological data for the disease are then fitted to curves which take into account the number of clones of lymphoid cells, and the number of mutations in each clone, which 
are necessary to produce the altered growth-signal. The author demonstrates that data for the site of attack of dental decay and for the site of onset of a number of diseases can also be fitted to such curves. Finally he shows that epidemiological data for three virus diseases (poliomyelitis, hepatitis and mumps) can also be fitted to such curves and interprets this as showing that these diseases can only affect a genetically-determined group of people in which a particular "forbidden-clone" of cells has already arisen. The reviewer would have been much happier had the author presented even a single disease or ageing-process in which the data could not be fitted to a form of the standard curve and thus could not be explained by the general theory. Some readers may not agree with all the molecular biology invoked to account for the high rates of somatic mutation the theory requires.

On balance, I was stimulated and intrigued by this book but not convinced of the truth of the general theory of growth it puts forward ... yet.

\section{J. G. M. SHIRE}

University of Cambridge, Department of Genetics

PLANT CHIMERAS. W. Neilson-Jones. Methuen and Co. Ltd., London. Second Edition, 1969. Pp. viii+123. 25s.

The title of the first edition, published in 1934, of this Methuen Monograph on Biological Subjects was " Plant Chimaeras and Graft Hybrids ". Although graft hybrids has been omitted from the title of the second edition and although, as the author states, " the burdo is at present an entirely hypothetical structure ", the ghost of the graft hybrid hypothesis haunts much of this book.

Two courses were open to the author in producing a second book on plant chimeras. First he could revise and rewrite the first edition or secondly he could produce an entirely new book. He chose the first alternative. The treatment of the subject is therefore historical as in the first edition and not systematic and comprehensive. Although some substantial changes have been made, most of the changes are small, and only 36 of the 134 references were published after 1933.

A more useful book could have resulted from a complete rewrite. Modern explanations of the structure and behaviour of plant chimeras are based on a modification of the tunica-corpus hypothesis of Schmidt (1924). This modification - the existence of three independent layers, L1, L2 and L3, at the stem apex in many dicotyledons--was derived mainly from the work of Satina, Blakeslee and Avery (1940) on colchicine-produced, diploid-polyploid periclinal Datura chimeras. Mention of this work is delayed until the final chapter of the monograph whereas in a complete rewrite it could have come at the beginning of the book to be followed by an account of how chimeras originate and how their structure can be investigated. As it is, a student interested in plant chimeras would be better advised to read two papers recommended by the author in his preface, Clowes (Heredity, 11, 141) and Tilney-Bassett (Heredity, 18, 265), rather than this monograph. The student should also read Dermen (1960, Am. Hort. Mag., 39, 123), a reference not given by Neilson-Jones.

Many minor criticisms can be made. There are, for example, better references than Gates (1924) for the origin of tetraploid cells and more is now 